\title{
THE FRACTIONATION OF THE IODINE OF THE BLOOD IN THYROID DISEASE
}

\author{
BY H. J. PERKIN AND LEWIS M. HURXTHAL \\ (From the Research Foundation and the Department of Internal Medicine, The Lahey Clinic, \\ Boston)
}

(Received for publication June 20, 1939)

Investigations concerning the level of iodine in the blood have been an aid in the better understanding of the metabolism of iodine in normal individuals and in patients with goiter. Experimental studies have established a relation between the thyroid gland and the metabolism of iodine. Clinical observations have shown that the abnormal physiological processes manifest in exophthalmic goiter may be alleviated by effecting transitory involution of the hyperplastic thyroid tissue with iodine medication and subtotal resection of the thyroid gland. It is generally agreed that clinical hyperthyroidism is associated with the release of abnormal amounts of iodine from the thyroid. In this connection, the affinity of the thyroid gland for iodine, together with the capacity of thyroid tissue to synthesize organic iodine compounds, plays an important rôle. Based on the foregoing, the quantitative estimation of the organic iodine in blood should be a closer index of the amount of thyroid secretion than assumptions based on total blood iodine analyses. The purpose of the present communication is to report the results of a study of the fractionation of the iodine in the blood in cases of nontoxic goiter, exophthalmic goiter and primary myxedema.

The quantitative estimation of the iodine in the blood is not a simple procedure. The additional technic of fractionating the blood iodine adds greater complexity. A satisfactory method of fractionation should be accurate to the degree that the sum of the iodine analyses of the two fractions should equal the iodine analysis of an aliquot amount of untreated whole blood. In addition, it is important to know approximately the chemical nature of the iodine recovered in each of the fractions. The limits of the method of blood iodine fractionation can best be estimated by adding specific forms of iodine to blood and determining in which fraction the iodine is recovered.

In this present study, an alcohol precipitation method was used for fractionating the iodine of the blood. The procedure was as follows: $20 \mathrm{cc}$. of blood is secured by venous puncture; $10 \mathrm{cc}$. of this blood is placed in a clean dry test tube for total iodine analysis, the remaining $10 \mathrm{cc}$. of blood is placed in a test tube containing a sufficient amount of iodine-free sodium oxalate to prevent clotting. The sample of oxalated blood is added directly to 10 volumes of ethyl alcohol. The precipitate is separated from the alcohol-blood mixture by filtering through a Whatman (Number 5) filter paper. The residue in the filter paper is washed 3 times with alcohol, using 15 cc. each time. The filter paper containing the precipitate (the so-called organic iodine fraction) is placed directly in a nickel crucible for iodine analysis (1). The filtrate (the so-called inorganic iodine fraction) is evaporated to dryness and transferred to a nickel crucible for iodine analysis. By exercising care to avoid contamination and loss of iodine (2) in the above procedure, the sum of iodine analyses of the 2 fractions should equal the iodine analysis of the sample of untreated blood.

The adequacy of the above method in fractionating the iodine of the blood was determined in the following manner: A supply of oxalated beef blood was secured from the abattoir. Six samples of $10 \mathrm{cc}$. each of this blood were used for total blood iodine analysis. To an additional 5 samples (10 cc. each), 3.8 micrograms of iodine in an organic form were added and total iodine analysis was carried out. These estimations constituted the control results for the fractional analyses. Five samples $(10 \mathrm{cc}$. each) were fractionated according to the procedure outlined above. To an additional 5 samples, 3.8 micrograms of iodine in an organic form were added and, after mixing, these bloods were fractionated for their iodine content. To another 5 samples of $10 \mathrm{cc}$. each of blood, 2.5 micrograms of iodine as inorganic 
iodide were added and, after mixing, the bloods were fractionated. The results of analysis of the above procedures are shown in Table I.

TABLE I

\begin{tabular}{|c|c|c|c|}
\hline & $\begin{array}{c}\text { Average } \\
\text { total } \\
\text { blood } \\
\text { iodine }\end{array}$ & $\begin{array}{c}\text { Average } \\
\text { organic } \\
\text { blood } \\
\text { iodine }\end{array}$ & $\begin{array}{c}\text { Average } \\
\text { inorganic } \\
\text { blood } \\
\text { iodine }\end{array}$ \\
\hline $\begin{array}{l}10 \text { cc. of blood } \ldots \text { cc. of blood }+3.8 \text { micrograms } \\
\text { of organic iodine } * \ldots \ldots \ldots \ldots \\
10 \text { cc. of blood } \ldots \ldots \ldots \ldots \ldots \\
10 \mathrm{cc} \text { of blood }+3.8 \text { micrograms } \\
\text { of organic iodine } \ldots \ldots \ldots \ldots \ldots \\
10 \mathrm{cc} \text { of blood }+2.5 \text { micrograms } \\
\text { of inorganic iodine } f \ldots \ldots \ldots \ldots\end{array}$ & $\begin{array}{c}\text { micro- } \\
\text { grams } \\
0.85 \\
4.62\end{array}$ & $\begin{array}{c}\begin{array}{c}\text { micro- } \\
\text { grams }\end{array} \\
0.82 \\
4.46 \\
0.84\end{array}$ & $\begin{array}{l}0.12 \\
0.24 \\
2.65\end{array}$ \\
\hline
\end{tabular}

* Thyroid proteose was used.

$\dagger$ Potassium iodide was used.

As will be seen from Table I, the average total blood iodine analysis was 0.85 micrograms per $10 \mathrm{cc}$. The actual error was \pm 0.12 micrograms. The recovery of iodine was satisfactory in the samples of blood to which 3.8 micrograms of organic iodine were added. In the fractionation of the whole blood, the organic iodine result was 0.82 micrograms per $10 \mathrm{cc}$. and the inorganic iodine, 0.12 micrograms. Although the sum of these 2 fractions exceeds the total iodine analysis of 0.85 micrograms, the results are still within the limits of actual error. In the fractionation of the blood samples to which the organic iodine compound was added, the recovery of iodine was almost complete in the organic blood iodine fraction. The slight increase in the inorganic fraction (0.24 micrograms) was attributed to a small amount of inorganic iodine present in the thyroid proteose. In the fractionation of the blood samples to which the inorganic iodine was added, the additional iodine was quantitatively recovered in the inorganic blood iodine fraction.

The organic iodine compound used in the above experiments was a proteose made from human thyroid tissue by Dr. W. T. Salter, Harvard Medical School, Boston, Massachusetts. This thyroid proteose has a molecular weight of approximately 7000 . Thyroxine (molecular weight of 777), when placed in solution and added directly to blood, cannot be completely recovered in the organic fraction by the above methods. Thus it would appear that the alcohol precipitation method used in fractionating the iodine of the blood was only capable of recovering in the so-called organic fraction iodine compounds with a molecular weight of 7000 and greater. The foregoing data are considered to establish the accuracy and the limitations of the method used in the present study of the fractionation of the iodine in the blood.

Fractional analysis of the blood iodine has been carried out on 218 individual patients. The cases have been divided into groups dependent upon the degree of thyroid activity as clinically estimated. The cases included 65 patients with nontoxic adenomatous goiter (normal), 98 patients with exophthalmic goiter who had never received any iodine medication, 38 patients with exophthalmic goiter who had received iodine for some time (at least a month) up to 24 hours prior to the blood iodine analysis, 7 patients with nontoxic goiter who had likewise received iodine, and 10 patients with untreated primary myxedema. Total blood iodine analyses and fractional blood iodine analyses were carried out in each case. The average blood iodine results of each group of cases are shown in Table II.

TABLE II

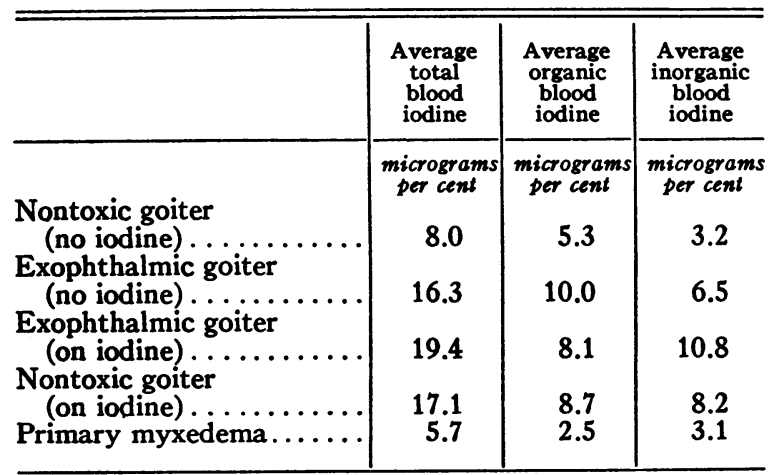

As will be seen from Table II, of the total blood iodine of 8.0 micrograms per cent of the nontoxic goiter group, 5.3 micrograms of iodine were present as organic iodine. ${ }^{1}$ The difference obtained by actual iodine estimation, amounting to 3.2 micrograms per cent, was inorganic iodine. In the group of patients with exophthalmic goiter which had not received iodine, the organic blood

1 The term organic blood iodine used throughout designates the iodine recovered in the alcohol insoluble fraction (see method). 
iodine was nearly twice that of the nontoxic goiter group, being 10.0 micrograms per cent. There appeared to be no correlation between the increase in the organic blood iodine and the elevation in metabolism in individual cases. The proportion of organic to inorganic iodine in the toxic goiter group was approximately the same as that found in the nontoxic goiter group. In the exophthalmic goiter group which had received iodine, the organic blood iodine was 8.1 micrograms per cent. This value was less than that found in the exophthalmic goiter group not receiving iodine. In individual cases, the decrease in organic blood iodine was not found to be proportional to the decrease in metabolism or the clinical improvement. The total blood iodine of the toxic goiter group receiving iodine was considerably elevated but the additional iodine was present in an inorganic form. In the nontoxic goiter group in which iodine was given, the organic iodine in the blood was greater than that of the nontoxic goiter cases in which iodine was not given. There appeared to be a similarity in the results of the toxic goiter group and the nontoxic goiter group, both of whom had received iodine. The average organic blood iodine of the myxedema cases was 2.5 micrograms per cent. This value was only onehalf that of the nontoxic goiter group and onequarter that of the cases of exophthalmic goiter. The inorganic blood iodine in the myxedema group was proportionately greater than in the other groups not receiving iodine. The results are shown graphically in the accompanying chart.

Attention is now directed to the interpretation of the above results. It is conceded that thyroid tissue has a particular affinity for iodine. In this connection, iodine absorbed from the intestinal tract, chiefly in an inorganic form, is retained and synthesized into specific iodine compounds within the thyroid gland. These iodine products secreted into the circulatory system presumably influence the rate of metabolism. Evidence favoring such a view lies in the fact that inorganic iodine medication (potassium iodide and Lugol's solution) is ineffective in increasing the oxygen consumption of athyroid individuals or of those in whom the thyroid gland has atrophied. In keeping with this theory, the organic blood iodine level in the above group of myxedema cases was low: the relative increase in the inorganic blood iodine of these cases suggests an inability of the thyroid gland to synthesize iodine into an organic form. It is interesting to note that reports in the literature have indicated that the total blood iodine is low in cases of myxedema $(3,4)$. This is not, however, of diagnostic significance due to overlapping with the range of that found in normals. Estimation of the organic blood iodine may prove to be of greater value in the diagnosis of thyroid insufficiency.

In cases of exophthalmic goiter, an association would appear to exist between the loss of colloid and iodine from the thyroid gland and the increase in the blood iodine level and urinary excretion of iodine. This correlation has been offered as evidence that a true hyperthyroidism exists in cases of exophthalmic goiter (5). If the increase in blood iodine derives from the thyroid gland, there should be a relative increase in the organic iodine in the blood. The present results lend themselves to such a view since the organic blood iodine in the cases of exophthalmic goiter was twice that found in cases of nontoxic goiter and 4 times that present in cases of myxedema. Since no correlation was evident between the level of organic blood iodine and the basal metabolic rate, one should bear in mind the possibility that the increase in metabolism may be associated with the liberation or synthesis of organic iodine compounds not necessarily formed within the thyroid gland. Mention should also be made of the fact that these results are the average values based on a group study and are not necessarily applicable to individual cases. The presence of an elevated or normal organic blood iodine was related to the duration of symptoms in these cases of exophthalmic goiter. The relationship has previously been established for the total blood iodine (6).

A regression of the signs and symptoms in patients with hyperthyroidism on iodine treatment (that is, 10 minims Lugol's solution 3 times daily) is an established fact. The clinical improvement is associated with an involution of the acinar elements of the thyroid gland. This histological change has been regarded as evidence of a reduction in the secretory capacity of the thyroid. In connection with this view, Holst, Lunde, Closs and Pederson (7) and Lunde, Closs and Pederson (8) reported that iodine medication in cases 


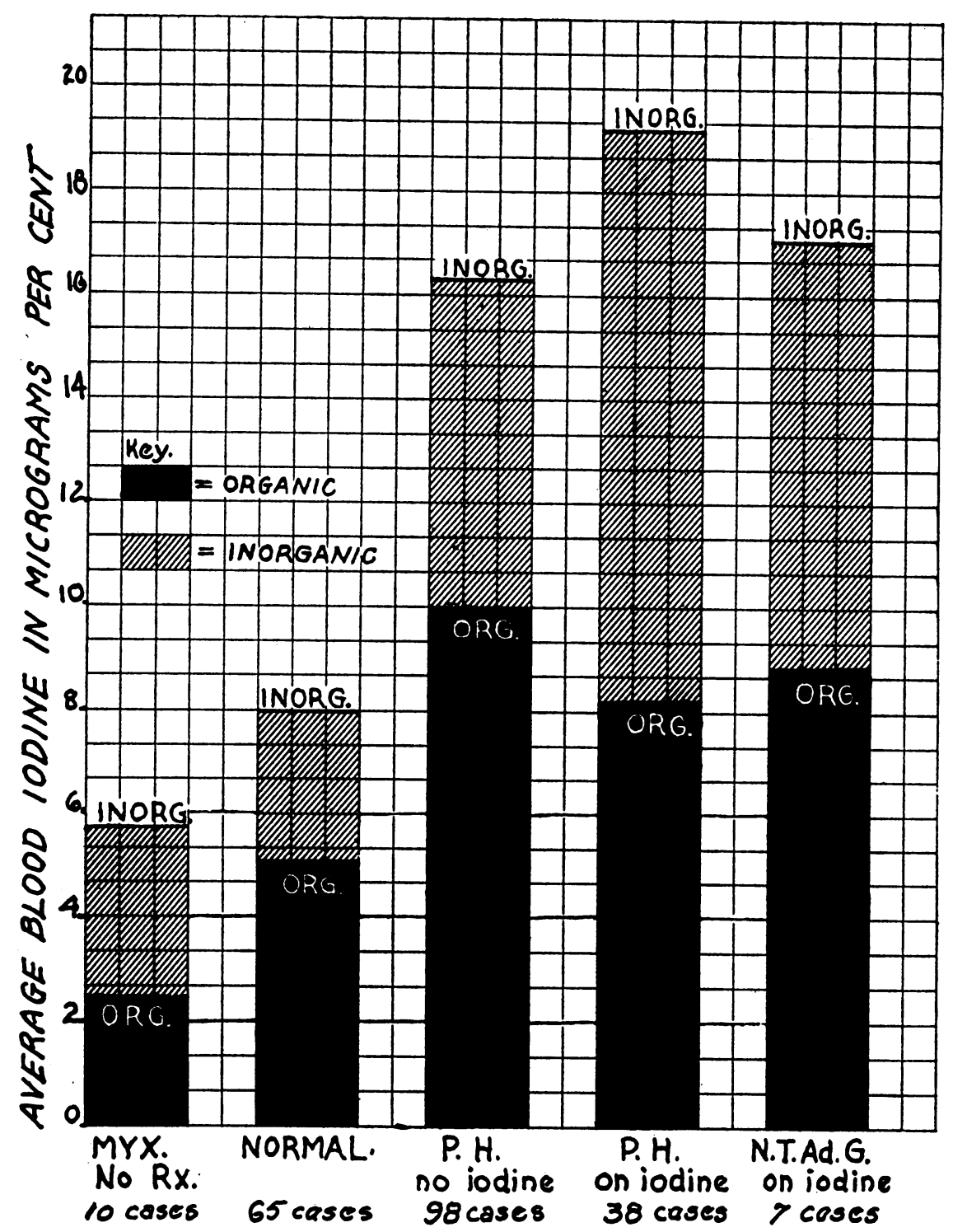

Fig. 1. The Relation of the Organic and Inorganic Iodine of the Blood to the Total Blood Iodine

of hyperthyroidism results in a decrease in the organic blood iodine. They presented evidence that the organic blood iodine decreased to normal proportionately with the basal metabolic rate. Using a method of alcohol precipitation followed by Soxhlet extraction, it was their opinion that the organic blood iodine fraction contained the active principle of the thyroid gland. Dodds, Lawson and Robertson (9), using similar methods of study were unable to confirm these observations. Relative to the aforementioned studies, the recent experimental observations of
Trevorrow (10) on the nature of the iodine in blood are of interest. Our results (see Table II) showed that the average organic blood iodine of patients with exophthalmic goiter receiving iodine was less than in patients not receiving iodine. These results, however, can only be interpreted as a general principle derived from a group study. Individually, exophthalmic goiter cases, not having had iodine, have been noted with a normal or even a subnormal organic blood iodine. Iodine treatment in these cases may result in an increase in the organic blood iodine associated with a 
clinical improvement of the patient. The effect of iodine treatment on the organic blood iodine may well be influenced by the time the blood analysis was done in relation to the last dose of iodine received and to the length of time iodine was administered. Different results with diverse interpretations might have been secured had the blood for analysis been taken at a different time. However, with these reservations in mind, one may state that under certain conditions, iodine medication in cases of exophthalmic goiter results in a decrease in the organic iodine of the blood. Insofar as this organic blood iodine fraction comprises the products of thyroid secretion, it would appear that iodine medication in cases of hyperthyroidism decreases the amount of iodine secreted by the thyroid gland.

In patients with nontoxic goiter without signs or symptoms of hyperthyroidism, but who were receiving iodine, the finding of an elevated organic blood iodine is difficult to explain. The results indicate that apparently normal individuals, if given iodine, may show an increase in the organic iodine of the blood. This observation suggests an explanation of the inability of iodine therapy to control completely the signs and symptoms of clinical hyperthyroidism.

\section{SUM MARY}

$A$. A method for the fractionation of the iodine of the blood has been described: the limitations of the method have been established.

$B$. Compared with the normal,

1. A decrease in the level of the organic iodine of the blood was found in patients with primary myxedema.

2. Patients with exophthalmic goiter who had not received iodine therapy were found to have an increase in the level of organic iodine in the blood.

3. A relative decrease in organic blood iodine was found in patients with exophthalmic goiter following iodine medication.

4. Patients with nontoxic goiter receiving iodine showed a relative increase in the organic iodine of the blood.

\section{BIBLIOGRAPHY}

1. Perkin, H. J., Determination of iodine in blood. Biochem. J., 1933, 27, 1078.

2. Perkin, H. J., and Cattell, R. B., The practicability and significance of blood iodine estimations. New York State J. Med., 1936, 36, 1033.

3. Schittenhelm, A., and Eisler, B., Der Blutjodspiegel in seiner pathologisch-physiologischen und klinischen Bedeutung. Klin. Wchnschr., 1932, 11, 6.

4. Elmer, A. W., and Scheps, M., The iodine content of blood and of urine and the basal metabolic rate; their value in the diagnosis of the function of the thyroid gland. Acta med. Scandinav., 1934, 82, 126.

5. Curtis, G. M., Davis, C. B., and Phillips, F. J., Significance of the iodine content of human blood. J. A. M. A., 1933, 101, 901.

6. Perkin, H. J., and Lahey, F. H., Exophthalmic goiter. Relation between the blood iodine level and the duration of symptoms in 305 cases. Arch. Int. Med., 1938, 61, 875.

7. Holst, J., Lunde, G., Closs, K., and Pederson, O. C., Uber den Inneren Jodstoff wechsel Bei Primären Thyreotoxikosen (Primär-Basedow). Klin. Wchnschr., 1928, 7, 2287.

8. Lunde, G., Closs, K., and Pederson, O. C., Untersuchungen über den Jodstoffwechsel. Biochem. Ztschr., 1929, 206, 261.

9. Dodds, E. C., Lawson, W., and Robertson, J. D., Variations in the iodine content of the blood in hyperthyroidism and nontoxic goiter. Lancet, 1932, 223, 608.

10. Trevorrow, V., Studies on the nature of iodine in blood. J. Biol. Chem., 1939, 127, 737. 